\title{
CHRISTINE DE PIZAN E A EDUCAÇÃO DE MULHERES NO ALVORECER DA MODERNIDADE
}

\author{
CHRISTINE DE PIZAN AND THE EDUCATION OF WOMEN IN THE DAWN OF THE MODERN \\ ERA
}

https://orcid.org/0000-0003-4812-7628 Anna Beatriz Esser dos Santos A

${ }^{\text {A }}$ Universidade Iguaçu (UNIG), Nova Iguaçu, RJ, Brasil

Recebido em: 29 abr. 2021 | Aceito em: 30 jum. 2021

Correspondência: Anna Beatriz Esser dos Santos (annaesser @ homail.com)

\begin{abstract}
Resumo
Discussões sobre a figura da mulher, ou das mulheres, cresceram no campo da história nas últimas décadas, reforçando produções que repensaram o modo de contar sobre estas agentes históricas. Contudo, a relação de produção histórica em que se fabricavam significados por vezes indiferentes a tais atrizes modificou-se, passando estas últimas a fazerem parte do círculo dos temas atuais da academia. Propomo-nos, então, a trazer a reflexão sobre a educação feminina e as múltiplas significações que esta constrói a partir dos condicionantes associados à existência social da mulher. Neste sentido, será analisada a perspectiva sobre educação de mulheres de uma figura que debateu e compartilhou a cena com os estudiosos do início do século XV, Christine de Pizan (1364-1430), criada na corte francesa de Carlos V. Em A Cidade das Damas, a autora fez reivindicações em nome das mulheres, afirmando que a diferença e desigualdade entre homens e mulheres era relativa ao espaço que cada um recebia.
\end{abstract}

Palavras-chave: educação; mulheres; Christine de Pizan.

\section{Abstract}

The debate about women and gender have grown in the field of history in recent decades, reinforcing productions that have rethought the way of telling stories about these historical agents. However, the relation of historical production in which the production about them were sometimes indifferent has changed, latter becoming part of the circle of current academy themes. We propose to bring the subject of female education and the multiple meanings that it builds from the conditions associated with the social existence of women. In this sense we will analyse the perspective on women's education of a figure who debated and shared the scene with the scholars of the early 15th century, Christine de Pizan (1364-1430), created in the French court of Carlos V. In The City of Ladies, the author made claims on behalf of women, stating that the difference and inequality between men and women was relative to the space that each one received in society.

Keywords: education; women; Modernity. 


\section{Introdução}

Por volta do período de produção de Christine, no século $\mathrm{XV}$, a mulher tinha sua construção imagética definida pelo olhar masculino que a colocava como uma figura frágil, inconstante e sedutora, que precisava ser sempre guiada por um homem, que deveria ser seu "cabeça". No tocante ao ideal de conduta feminina, os clérigos transmitiam suas ideias através de pregações, especialmente com o surgimento das ordens mendicantes. No século XIII, enfatizavam-se os exempla, pequenas histórias baseadas em lendas ou no cotidiano, que serviam de base para a pregação. Estes pregadores empenhavam-se em atacar a vaidade feminina e a infidelidade, pondo em oposição virtudes necessárias, como a castidade e a obediência (LEITE, 1999), em um tipo de mulher concebido com base no modelo bíblico de Eva.

Com a ascensão da burguesia, surgem tratados voltados para assuntos bastante práticos, ensinando a mulher a ser submissa ao marido e a saber governar a casa. Ao longo dos dois últimos séculos da Idade Média, o pensamento da burguesia ascendente caracterizou boa parte da literatura desse período, com extremas críticas à personalidade da mulher (VAUCHEZ, 1995). Sentimentos como a vaidade, a ambição e a ingratidão caracterizavam diversas personagens de obras de autores da época. Muitas produções foram elaboradas com o intento de ilustrar os infortúnios que assinalavam a vida de um homem casado com um tipo de mulher concebido como "megera". Estes ataques à mulher estão amplamente vinculados a um questionamento do sacramento do matrimônio (MACEDO, 1999).

Todavia, essa construção possuía diversas ramificações, pois a figura da mulher poderia também seguir o modelo de Maria Madalena, que é a pecadora arrependida, a que se redime. Vemos que as atitudes de Jesus no Novo Testamento para com a mulher estrangeira (samaritana) e a adúltera (depois associada à Maria Madalena, condenada ao apedrejamento) eram de igualdade e compaixão.

Além desses modelos de mulher, temos a figura que exemplifica a representação máxima de virtude: Maria, Mãe de Jesus, que se mostrou um exemplo de resignação, boa conduta e amor a Deus ao enfrentar todas as adversidades para dar à luz e criar o Salvador, aquele que guiaria os homens - resgatando, assim, os pecados cometidos por Eva: Dessa forma, a mulher não será, portanto, mais o instrumento material através do qual se exerce a tentação 
de Satanás: a Virgem resgatou o pecado original de Eva, a primeira tentadora, e a mulher já não é considerada perigosa como tal (PILOSU, 1995, p. 32).

O período entre o final do século XIV e o século XV caracterizou-se por diversas mudanças, desde o fortalecimento político das cidades até as novas movimentações sociais (MISKIMIN, 1998). Em alguns momentos, as mulheres chegaram a dividir com os homens desde as tarefas domésticas até os trabalhos no cotidiano, no caso das camadas mais populares. Trabalharam no ofício de pedreiras, comerciantes, sapateiras e, algumas vezes, sem o amparo masculino. As mulheres também poderiam tentar exercer sua autonomia nos conventos, onde as religiosas poderiam aprender a ler e escrever.

\section{Aportes teóricos}

Nossa reflexão permeia o papel da mulher numa sociedade no alvorecer da modernidade, verificando as condutas esperadas pela mulher e os elementos que constituem um comportamento que era idealizado e aquilo que era condenado pelo pensamento corrente do período. Analisamos, assim, as representações a respeito da construção da imagem dessas mulheres.

Quando nos referimos à construção, em especial de gêneros, estamos nos remetendo a algo que se opõe a ideias deterministas, e pensamos sobre a produção social dos sentidos (do que é masculino e feminino) a um processo que vem sendo construído ao longo do tempo.

Neste sentido, trabalharemos com as proposições teóricas elaboradas pela historiadora norte-americana Joan Wallach Scott (1995). A autora afirma que gênero é o saber a respeito das diferenças sexuais. Scott utiliza o conceito, aplicando-o segundo Michel Foucault, ou seja, como a compreensão produzida pelas culturas e sociedades sobre as relações humanas (SCOTT, 1995). Essa produção do saber encontra-se no social e envolve escolhas, interesses e relações de poder. Logo, consideramos que gênero e suas implicações possuem visão marcadamente politizada.

Para a autora, discutir gênero é abordar algo social. O conceito de gêneros sexuais apresenta-se para desconstruir a representação tradicional do feminino e do masculino, ao entender que homens e mulheres são socialmente produzidos pelo discurso dominante e, também por crenças, imagens e símbolos presentes nas diferentes culturas. Podemos, então, com nossa fonte, observar e verificar novos modelos, novas representações de como entendemos as mulheres do período. 
Nossa fonte configura-se como um texto literário que contribui para a construção de identidades sociais, de relações sociais e de sistemas de conhecimento e crença, cuja reprodução e transformações (possíveis) cabem às práticas discursivas de que a literatura é um veículo. Neste sentido, podem representar e/ou reproduzir ideologias, que entendemos como,

significações/construções da realidade (o mundo físico, as relações sociais, as identidades sociais), que são construídas em várias dimensões das formas/sentidos das práticas discursivas e que contribuem para a produção, a reprodução ou a transformação das relações de dominação (FAIRCLOUGH, 2001, p. 117).

Como nessa construção textual o aspecto da língua é essencial, esta pode ser entendida, por um lado, a partir de sua função na sociedade, como um meio de comunicação nos quais mensagens e informações são elaboradas e passadas, mas também se pode compreender a linguagem como a própria comunicação, que é constituída na sociedade, a reflete e é representada pela própria.

A respeito do papel da linguagem e sua importância para pensar as relações de poder no campo discursivo, as considerações de Bordieu são úteis para a análise de nossa fonte. Ele explica que se pode conferir uma eficiência propriamente simbólica de construção da realidade, isto porque aquela estrutura a noção que os agentes sociais têm do mundo e como se operam as relações nesse mundo. Assim, a língua pode ser compreendida como um sistema simbólico que constitui instrumentos de conhecimento e de comunicação, de visões de mundo e de percepção do mundo social. O historiador prossegue:

A percepção do mundo social é produto de uma dupla estruturação social: do lado objetivo, ela está socialmente estruturada porque as autoridades ligadas aos agentes ou às instituições não oferecem a percepção de maneira independente, mas em combinações de probabilidade muito desigual (...); do lado subjetivo, ela está estruturada porque os esquemas de percepção e de apreciação, (...) são produtos das lutas simbólicas anteriores e exprimem, de forma mais ou menos transformada, o estado das relações de força simbólica (BOURDIEU, 2004, p. 139-140).

As considerações de Bourdieu são pertinentes para essa discussão, pois através delas se pode precisar de que forma a linguagem exerce um poder e se constitui em um instrumento que age sobre o mundo. É através deste poder simbólico percebido na linguagem que o caráter social desta é reafirmado. A força das palavras se exerce na sua ação comunicativa, pois elas propagam valores, significados, ideologias que perpassam os agentes sociais se configuram como formas de dominação e exercício de poder. 
Neste sentido, acreditamos que o conceito habitus de Pierre Bourdieu, cuja obra extensa e a inovação conceitual o consolidaram como um dos maiores expoentes da História da Sociologia, seja importante para a nossa pesquisa, pois também analisaremos como as ideias da sociedade foram sendo compreendidas e apreendidas por Christine ao longo de seus livros. Buscando um conceito conciliatório que compreendesse tanto a influência da sociedade sobre o indivíduo quanto a autonomia relativa do indivíduo frente à sociedade, o sociólogo francês trabalhou a noção de habitus, uma forma de observar no individuo as disposições herdadas do contexto histórico e social em que foi socializado.

A noção de habitus é, deste modo, orientada para o senso prático, para a ação social levada a cabo como atitudes incorporadas e não necessariamente refletidas na ação. Ela permite dissociar o isolamento entre agentes sociais e sociedade, visto que a sociedade é parte constitutiva do que o agente é, através da introspecção de valores que o caracterizam e o definem. É um sistema adquirido de preferências, de princípios de visão e de divisão (o que comumente chamados de gosto), de estruturas cognitivas duradouras (que são essencialmente produto da incorporação de estruturas objetivas), de esquemas de ação que orientam a percepção da situação e a resposta adequada (BOURDIEU, 1996, p. 42).

O habitus, apesar de orientar os comportamentos do agente a partir de um senso prático, não determina as escolhas, mesmo que estas sejam feitas a partir de variáveis habitualmente admitidas pelo contexto histórico vigente. Trata-se, nas palavras de Bourdieu, de sistemas de disposições transponíveis apesar de estruturados, sem estarem necessariamente associados à obediência de regras coletivamente organizadas e orquestradas (BOURDIEU; WACQUANT, 1992).

Neste sentido, é importante ressaltar que a região onde cresceu Christine possuía, para a época, uma vida cultural propícia para a produção de diversos estilos de escrita, e ela circulava na corte em que mantinha contatos, os quais possibilitavam seu ofício. Ao mesmo tempo, Pizan vivia numa atmosfera repleta de valores e designações dadas à figura feminina que não a deixava escapar das atribuições morais determinadas socialmente, sem por isso, contudo, ter expurgado de sua literatura o espaço criativo para desvios e descontinuidades.

\section{O espaço de produção feminina}

Christine de Pizan nasceu em Veneza em 1365, porém mudou-se para França quando tinha cinco anos, porque seu pai, Tommaso di Bevenuto da Pizzano, então professor da Universidade de Bolonha, fora contratado para ser astrólogo e médico pessoal de Carlos V. 
Devido a tal fato, Christine recebeu a mesma educação das princesas, uma formação baseada no ensino das humanidades (LE GOFF, 2006). Pizan aprendeu a ler sobre as mais variadas questões e a pensar sobre o conhecimento que adquiria, dando exemplos de autores clássicos com os quais teve contato ao longo de sua vida e mostrando grande domínio de suas obras (LEMARCHAND, 2001). Acredita-se que suas reflexões sobre a necessidade das mulheres, assim como os homens, terem acesso ao conhecimento e aos estudos foi sendo desenvolvida nesta época (LEITE, 2008).

A mãe de Christine apoiava a instrução da filha ser voltada aos afazeres domésticos e que os estudos não deveriam ser os mesmos de um homem (algo considerado impróprio na época). Christine dedica, inclusive, um trecho de A cidade das Damas para discutir sobre as posturas sociais, as de seu pai e as de sua mãe, frente a instrução e educação das jovens mulheres:

\begin{abstract}
"De hecho, como ves, no todos los hombres, y sobre todo los más cultos, piensan que está mal que las mujeres estudien. Sí es cierto que así opinan los que menos instrucción tienen, porque les disgustaría mucho que unas mujeres supieran más que ellos.

Tu padre, gran sabio y filósofo, no pensaba que por dedicarse a la ciencia fueran a valer menos las mujeres. Al contrario, como bien sabes, le causó gran alegría tu inclinación hacia el estudio. Fueron los prejuicios femeninos de tu madre los que te impidieron durante tu juventud profundizar y extender tus conocimientos, porque ella sólo quería que te entretuvieras en hilar y otras menudencias que son ocupación habitual de las mujeres" (PIZÁN, 2001, p. 199).
\end{abstract}

Desde muito jovem, Christine percebeu que nascer mulher era algo determinante na sociedade em que vivia, seu papel seria o de cumprir os deveres de esposa e mãe e as únicas tarefas bem aceitas socialmente eram as relacionadas ao espaço privado (LEMARCHAND, 2001). Foi questionando este pensamento que Pizan baseou a escrita de suas obras.

Christine casou-se aos quinze anos com Estienne de Castel, este período do casamento é lembrado com felicidade por Pizan em suas histórias. Em 1380, um pouco antes da morte de Carlos V, Castel foi nomeado secretário do Rei (FAMIGLIETTI, 1986, p. 35). A década de 1380 também foi bastante conturbada para a França. O filho de Carlos V, que já era órfão de mãe, estava com apenas onze anos quando o pai morreu. Embora Carlos VI tenha sido coroado rei em 1381, quem governava de fato eram seus tios paternos, duques de Anjou, de Berry, da Borgonha e de Bourbon, pois ele era ainda menor de idade (LEMARCHAND, 2001). Carlos VI conseguiu aos 20 anos livrar-se da influência dos tios regentes com a ajuda do Condestável Olivier de Clisson, inimigo político dos Duques de Berry e da Borgonha (LAIGLE, 1912). 
Para Christine, o período também foi conturbado. Seu pai falece em 1386, um pouco depois seu marido também, deixando-a viúva após dez anos de casamento, e sua família perde sua posição e prestígio na corte (LAIGLE, 1912). Sem a presença do pai e do marido, Christine tinha sobre sua tutela sua mãe e filhos, a quem precisava sustentar. Com a morte de Castel, muitos credores aproveitaram-se da situação e tomaram os bens da viúva, algo que era muito comum na época, uma vez que normalmente a esposa não tinha conhecimento dos negócios em que o marido falecido estivera envolvido. Pizan, porém, tendo conhecimento das leis, foi em busca do que lhe era devido e de seus direitos. Lutou nos tribunais, um espaço essencialmente masculino, e mais tarde conseguiu reaver os bens que legalmente pertenciam a ela e aos seus filhos (WILLARD, 1963), como sugere em sua obra: "Rechazad a los hipócritas que se valen de las armas de la seducción y de falsos discursos para robaros vuestros más preciados bienes, el honor y una hermosa fama" (PIZÁN, 2001, p. 274).

Enquanto isto, para prover sua casa e a família, passou a escrever, em especial para as damas da corte. Christine consegue circular por entre as disputas, recebe encomendas dos diversos grupos da época, pois consegue consagrar as figuras importantes de cada casa regente em suas obras, principalmente através das figuras femininas (LAIGLE, 1912) ${ }^{\mathrm{i}}$.

Pizán lançou suas primeiras publicações por volta de 1394, mas alcançou maior notoriedade com a publicação de L'Epitre au Dieu d'Amours em 1402, em que inseriu as suas discussões sobre o Roman de La Rose, de que trataremos mais à frente. Aquelas damas e princesas francesas que influenciaram, ajudaram e financiaram Christine estão presentes no capítulo LXVIII d'A Cidade das Damas. Dentre as mulheres elogiadas por Pizán estão na ordem: Isabel da Bavária, esposa de Carlos VI e rainha da França; Duquesa de Berry, esposa do rei João da França, irmão de Carlos V; Valentina, filha do Duque de Milão; Margarida, duquesa de Borgonha; Maria, condessa de Clermont; Duquesa de Holanda e condessa de Hainaut, filha de Filipe, o Bravo, de Borgonha; Anna, duquesa de Bourbon; Bonne, condessa de Saint-Pol; Anna, filha do duque Le Marche e esposa de Luís da Bavária:

"Yo, Cristina, retomé la palabra:

-Señora, ya que acabáis de recordar el ejemplo de una dama que vive todavía y que habéis citado otras damas de Francia, quiero preguntaros si no pensáis que sería justo que nuestra Ciudad albergara algunas de ellas y si no son tan dignas como las extranjeras.

-Ten por cierto, querida Cristina, que las hay de gran mérito y que me gustaría que fueran ciudadanas nuestras" (PIZÁN, 2001, p. 247). 
As disputas entre França e Inglaterra passavam por alguns momentos de trégua. $\mathrm{O}$ casamento do rei inglês Ricardo II com a filha de Carlos VI selou um acordo de paz entre os dois reinos, que estavam alternando momentos de guerra e paz desde 1337, com a chamada Guerra dos Cem Anos. Esta aliança veio a ser interessante à família de Christine de Pizan, pois possibilitou a ida de seu filho mais velho à Inglaterra, a fim de que fosse educado junto ao filho do conde de Salisbury, de onde regressou após três anos, sob a proteção do duque de Orleans. Seu filho depois passou a exercer a mesma profissão de Estienne de Castel, como secretário do rei. Este contato também permitiu a possibilidade de que algumas obras da escritora fossem traduzidas para o inglês (LAIGLE, 1912). Também durante este período, Pizan perdeu o filho mais novo e sua filha decide entrar no convento de Saint-Louis de Possy (ASTRIK, 1955). Christine foi tornando-se conhecida à medida que seus comitentes, como Isabel da Baviera, esposa de Carlos VI, presenteavam outros nobres com suas obras.

Suas experiências pessoais, suas relações com a corte, suas dificuldades e necessidades de sair do seu lugar de destino para se movimentar em espaços de domínio dos homens levaramna a refletir sobre a situação das mulheres e a questionar sobre os ataques que sofriam nas obras dos mais conceituados escritores.

Para demarcar seu espaço de discussão, Christine envolveu-se nos debates da chamada Querelle des femmes, que versava em torno do Roman de La Rose, poema escrito por Guillaume de Lorris no século XII. Na primeira parte do texto, há uma exaltação da figura da mulher com poemas em louvor ao amor. O enredo baseava-se na história do jovem que adentrava um jardim onde uma Rosa estava para desabrochar, tornando-se objeto de seu desejo. Para chegar perto da Rosa, ele contou com a ajuda de Bel Accueil, que o defendeu contra os inimigos Danger, Jalousie e Malebouche. A segunda parte, com cerca de dezoito mil versos, foi escrita cinquenta anos depois pelo padre Jean de Meung. Nesta parte acrescentam-se personagens como Raison, Nature e Genius. No trecho de Jean de Meung, a flor, símbolo do amor cortês, é colhida, não havendo mais um refinamento alegórico, a descrição do ato amoroso reduzindo a figura da mulher a um objeto de prazer (ESCUDERO, 2008). Neste poema, existem então duas escolas amorosas distintas: por um lado a escolha do amor cortês de Lorris, com temas clássicos do trovadorismo, fornece uma história de amor que serve como modelo educacional das classes nobres; por outro lado, a versão de Jean de Meung deixa a narrativa mais realista e direta, num estilo bastante diferente da primeira parte. A lição que fica ao final da segunda parte é que o relacionamento amoroso que não se destina à procriação fica improdutivo, estéril e suscetível às artimanhas femininas (ESCUDERO, 2008). 
A segunda parte do Roman de la Rose foi muito apreciada pelos escolásticos da época. Ao traçar um perfil feminino débil, os autores, mas principalmente Jean de Meung, foram decisivos para o aumento da noção de inferioridade das mulheres, colaborando para o recrudescimento da misoginia entre aqueles que tinham acesso a obras como esta nas universidades, espaço do qual as mulheres estavam alijadas. É nesse contexto que a querela se desenvolve, acerca do conceito de amor, das qualidades literárias de Jean de Meung e do papel das mulheres (ESCUDERO, 2008).

Jean de Montreuil, clérigo de Lille e, também secretário do rei Carlos VI, escreveu um tratado endereçado a Gontier Col, também secretário, conselheiro real e membro do alto clero, no qual defendia a segunda parte do poema. Foi neste momento que Pizan se envolveu na querela, posicionando-se contra o a visão do Roman de la Rose, ao redigir uma carta a Jean de Montreuil. Essa carta e o livro A Epístola ao deus do Amor, que atribui a responsabilidade dos dois sexos às questões referentes à paixão, insere a escritora neste debate de esfera masculina. As intensas trocas de cartas deste debate, que incluiu ainda o irmão de Gontier, Pierre de Col ao lado de Montreil e Jean Gerson, chanceler da Universidade de Paris, ao lado de Christine foram posteriormente compiladas em um dossiê, o qual foi dado a Isabel de Baviera, rainha regente no período. Jesús Escudero destaca, neste momento, como os argumentos de Christine contra a autoridade intelectual de Meung denotam um "nuevo tipo de identidad personal y literária" (ESCUDERO, 2008, p. 28), com uma mulher que tem consciência de suas habilidades argumentativas e inauguradora de toda uma tradição discursiva.

Christine conseguiu inserir-se no meio das discussões literárias e alcançou certo conhecimento por estar imersa nos debates e nas argumentações discursivas. Em 1405, como resultado das opiniões que foram sendo desenvolvidas com a querela, escreveu A Cidade das Damas, no qual questionou a autoridade masculina dos grandes pensadores e poetas que contribuíram para formar a tradição sob a decisão de fazer frente às acusações e insultos contra as mulheres.

\section{A educação de mulheres em A cidade das Damas}

As mulheres d'A Cidade das Damas de Pizan são pensadas de maneira metafórica, caracterizadas como pedras sólidas que estão construídas para representar uma defesa moral para todas as mulheres. Cada Dama tem seu papel definido e sua importância nas partes do livro: Razão é a responsável por fazer as fundações e os muros, demonstrando que a principal defesa desta cidade habitada por mulheres é a argumentação racional; Retidão constrói as casas, 
palácios e templos, usando como pedras para essas construções as vidas exemplares de mulheres de diferentes épocas e Justiça finaliza a cidade, convocando as primeiras moradoras, as mulheres que foram constantes em seu amor.

A primeira parte de seu livro é a construção, sob o comando da Razão, que a ajuda a marcar o terreno. Este terreno é o mesmo do campo literário, necessário às respostas para as argumentações masculinas, o que ela faz dialogando com Razão e defendendo as mulheres, demonstrando com exemplos porque elas mereciam ser defendidas. Dentre esses assuntos está o acesso a uma cultura intelectual refinada para as mulheres e grandes senhoras:

Por lo que me decís, Dama mía, la mujer es una creación muy noble. Sin embargo, dice Cicerón que un hombre no debe nunca servir a una mujer porque ponerse al servicio de alguien menos noble que uno mismo sería envilecerse.

Ella me respondió con estas palabras:

-El más grande es aquel o aquella que más méritos tiene. La superioridad o inferioridad de la gente no reside en su cuerpo, atendiendo a su sexo, sino en la perfección de sus hábitos y cualidades. (PIZÁN, 2001, p. 81-81)

Destaca também as mulheres instruídas e mulheres prudentes. Entre as que executaram atividades políticas e militares como a imperatriz Nicaula da Etiópia, também conhecida como a Rainha de Sabá, que foi muito poderosa; Fredegunda da França, que, por astúcia, tirou seu filho dos braços dos inimigos; e a rainha Blanche, que governou a França na menoridade do filho e depois ocupou um lugar principal em seu grupo de conselheiros. A intenção de Christine era mostrar que as mulheres têm capacidade de governar tão bem quanto qualquer homem, mostrando-as com prudência e com mentes esclarecidas para a política e para a justiça.

A seguir, a autora é guiada pela Retidão, convocada para a construção das torres, dos palácios reais e das nobres habitações. As mulheres que foram chamadas para traçar essas primeiras edificações foram as sibilas e profetisas, que com sua linguagem irão construir o refúgio das mulheres.

Ao fim da segunda parte do livro, Christine declarou que a cidade das damas estava finalizada e pronta para ser povoada. Dirigindo-se às mulheres de todas as condições, que amaram, amam ou amarão a virtude e a sabedoria, sua cidade não se situava em um tempo ou um lugar, ela era eterna, existiria enquanto houvesse pessoas que tivessem acesso ao seu livro.

Na terceira parte, Justiça, que fortificou a cidade, guiou Christine. Maria, Mãe de Jesus Cristo, foi coroada como rainha e as escolhidas para figurarem como imperatrizes foram as irmãs de Maria e Maria Madalena. Neste momento também foram escolhidas as intercessoras que seriam as santas mártires. Dedicado à vida contemplativa, esta parte do livro apresentou as 
santas como mulheres independentes e autossuficientes, mulheres que só se casaram com Deus e rejeitaram a submissão ao sexo masculino.

A autora convocou a todos e todas que encarassem sua cidade como um refúgio, uma fortaleza e, principalmente, como um exemplo de virtudes. Em seguida, dirigiu-se a todas as mulheres segundo seu estado civil, casadas, solteira e viúvas, indo além desta categorização, estendendo seu discurso a todos os estamentos sociais, pedindo-lhes que tomassem cuidado com as armadilhas que pudessem vir a seduzi-las.

Muitos dos trabalhos de Christine perpassam o tema da educação feminina, mas especialmente as duas obras analisadas. São escritos complementares, porém são diferentes entre si, tanto em estilo quanto na forma em que são tratados os temas. A Cidade das Damas, tendo sido resultado dos debates sobre o Roman de la Rose, configura-se como uma cidade alegórica, na qual as grandes e virtuosas mulheres podem viver a salvo das difamações dos homens. Christine povoa sua cidade com algumas figuras clássicas provindas da obra de Boccacio De mulieribus claris $^{i i}$ (ASTRIK, 1955), como santas e figuras femininas de sua época. Ela agrupa suas mulheres virtuosas, de modo a exaltar talentos e qualidades específicas em cada modelo. Pizan estava preocupada em demonstrar o intelecto feminino, sua coragem e suas virtudes morais. Esta obra caracteriza-se, segundo Susan Bell, por um objetivo triplo: de provar as capacidades femininas, de educar as outras mulheres pelo exemplo e de escrever uma história de mulheres (BELL, 1976). Em especial, Christine acaba por defender ideias sobre educação que estavam a par com o pensamento humanista do período: ela propunha, por exemplo, que meninas deveriam ser enviadas desde jovens para a escola, juntamente com seus irmãos e que a educação de meninas seria de maior benefício para elas do que para eles, pois o entendimento destas últimas é mais livre e afiado do que o dos rapazes (PIZÁN, 2001, p. 186).

De maneira geral, Christine buscava explicar em A Cidade das Damas a falta de mulheres nas universidades e os porquês de uma ausência intelectual feminina. Ela então, traça uma analogia entre homens e mulheres e entre cortesãos e camponeses, em que, ao fim, a diferenciação entre os gêneros residia na falta de educação e de conhecimento, sendo as mulheres também capazes de produzirem trabalhos originais e criativos (PIZÁN, 2001, p. 177178).

A construção da cidade tinha definido o papel da mulher nobre, pois aquelas que faziam parte da cidade tinham o direito de estar ali não por seu poder, riqueza ou nobreza, mas por mostrarem seu poder através da sabedoria, virtude, discernimento e justiça. A autora vai delimitando o perfil da mulher ideal, independentemente da sua condição social, etária ou 
familiar. Cabe ressaltar que o livro foi endereçado a todas as mulheres, desde as princesas até as mulheres pertencentes às classes subalternas, aconselhando de religiosas a prostitutas. Assim, qualquer mulher poderia se habilitar à Cidade das Mulheres, bastando estar condizente com a educação que lhe cabia, a partir da condição social em que cada uma delas vivia.

\section{Conclusão}

Christine produz, no século XV, obras que vão reivindicar o estudo como espaço de criação feminino. Conseguiu mover-se em um meio masculino por ter contatos e viver na corte. Conseguiu que sua voz fosse ouvida na sociedade em que vivia, primeiramente quando pleiteou seus direitos e tentou recuperar seus bens, depois quando passou a escrever como forma de sustentar a sua família.

A criação de sua cidade-refúgio era seu próprio livro, o qual propiciava a mulheres de diferentes religiões, épocas e condições se encontrarem. Seu pensamento não estava no passado ou no futuro longínquo. A realidade de seu sonho e utopia consistia na grande verdade de que, enquanto houvesse pessoas com acesso ao seu livro, a Cidade das Damas serviria novamente de abrigo, pois ela continha os exemplos perfeitos, para que todos tivessem como modelo a conduta daquelas que serviram como pedras de construção e das suas nobres habitantes.

Como a obra foi balizada pela moral cristã, Christine propôs a obediência feminina como uma virtude, embora tenha realizado uma ruptura dentro dessa relação de submissão ao insistir no direito da mulher de ter a mesma educação dos homens, pois argumentou favoravelmente à capacidade feminina. Defendendo também o direito das mulheres à palavra, a autora procurou restabelecer o sentimento de confiança no sexo feminino e combater ideias correntes na época. Ela deixou claro o seu objetivo de incluir todas as mulheres no seu projeto de valoração.

A construção de A Cidade das Damas tinha definido o papel da mulher verdadeiramente ilustre. Aquelas que fazem parte da cidade têm o direito de estar ali, não por seu poder, riqueza ou nobreza. A Cidade das Damas reservava-se àquelas mulheres que se ilustravam pela sabedoria, pelo discernimento e pela justiça ${ }^{\text {iii }}$ Destarte, qualquer mulher poderia se habilitar independentemente de sua condição social, bastando apenas que cada uma conhecesse o reto caminho a partir da condição social em que vivia.

Susan Bell acredita que Pizan é uma figura peculiar, pois esteve à parte da sociedade não somente por conta da perda de seus amigos, marido e pai, como também por conta da sociedade francesa. Ela não se considerava uma mulher intrinsecamente francesa por suas 
origens italianas; não era uma aristocrata, mas circulou na margem das cortes da Borgonha e França. Ela foi apoiada financeiramente por diversas famílias ducais, mas isso não significava que ela fazia parte do círculo próximo dessas famílias. Ela recebia por seus trabalhos, o que implica também em uma relação servil com seus empregadores. Por fim, ela fazia um trabalho essencialmente masculino, ela era, em uma época em que muitas outras não tinham a mesma situação, uma mulher das letras, uma escolástica mulher num espaço masculino (BELL, 1976).

Se no universo em que produziu Christine houve precedentes que colaboraram com a circulação de suas obras pelo público, parece-nos, contudo, que isso não desvinculou o feminino de uma regulamentação perante a produção escrita, justamente pelo fato do feminino ser pensado como fora do âmbito hierárquico de circulação intelectual. Atitudes de produção literária feminina, como a de Pizan e outras que a antecederam e sucederam, reivindicaram novas construções que possibilitaram mudanças de significações da figura feminina e a abertura de um espaço, ainda que pequeno, de produção intelectual de mulheres e para mulheres.

\section{Referências}

ASTRIK, Gabriel L. The Educational Ideas of Christine De Pisan. Journal of the History of Ideas, Vol. 16, No. 1 (Jan., 1955), p.3-21.

BELL, Susan. Christine de Pizan (1364-1430): Humanism and the Problem of a Studious Woman. Feminist Studies, Vol. 3, No. 3/4 (Spring - Summer, 1976), p.173-184.

BOURDIEU, P. Razões Práticas: sobre a teoria da ação. Campinas, SP: Papirus, 1996.

BOURDIEU, Pierre. O poder simbólico. Trad. Fernando Tomaz. Rio de Janeiro: Bertrand Brasil, 2004.

BOURDIEU, P. \& WACQUANT, L. J. D. Réponses: Pour une anthropologie réflexive. Paris: Editions du Seuil, 1992, p.68-89.

BOURDIEU, P. Estructura, habitus, prácticas. El sentido practico. Buenos Aires: Siglo XXI Editores, 2007.

ESCUDERO, Jesús A. Cristina de Pizán: identidad personal y memoria colectiva. AGORA Papeles de Filosofía,2008, p. 25-39.

FAIRCLOUGH, Norman. Discurso e mudança social. Trad. Izabel Magalhães et al. Brasília: Editora da Universidade de Brasília, 2001. 
FAMIGLIETTI, R.C. Royal Intrigue: Crisis at the Court of Charles VI, 1392-1420. Nova Iorque: AMS Press, 1986.

LAIGLE, Mathilde. Le livre des trois vertus de Christine de Pisan et son milieu historique et littéraire. Paris: Honoré Champion, 1912.

LE GOFF, Jaques. Os intelectuais da Idade Média. Rio de Janeiro: José Olympio, 2006.

LEITE, Lucimara. Christine de Pizan: uma resistência na aprendizagem moral da resignação. Tese de doutorado do Programa de Pós-Graduação em língua e literatura francesa e Estudos Medievais da Universidade de São Paulo, 2008.

LEITE, Márcia. M.S.B. Representações femininas na idade média: o olhar de Georges Duby. Sitientibus, Feira de Santana, n.1, jul/dez 1999, p. 37-50.

MACEDO, José R. A mulher na Idade Média. São Paulo: Contexto, 1999.

MISKIMIN, Harry. A Economia do Renascimento Europeu (1300-1600). Lisboa: Estampa, 1998.

PILOSU, Mario. A mulher, a luxúria e a Igreja na Idade Média. Lisboa: Estampa, 1995.

PIZÁN, Christine. La ciudad de las damas. Madrid: Siruela, 2001.

SCOTT, Joan W. Gênero: uma categoria útil de análise histórica. Educação \& Realidade. Porto Alegre, vol. 20, no 2, jul./dez. 1995, p. 71-99. VAUCHEZ, André. A espiritualidade na Idade Média Ocidental. Rio de Janeiro: Jorge Zahar, 1995.

\footnotetext{
'Christine dedica à Phillipe de Borgonha sua Mutacion de Fortune e é, posteriormente, contratada para escrever sobre Carlos V a obra intitulada Le Livre des Fais et bonnes Meurs du bon roy Charles

ii Conjunto de cento e quatro biografias de mulheres mitológicas e reais, publicada em 1374, que se configura como uma exortação de várias virtudes femininas.

iii Ibid.
} 